Check for updates

Cite this: RSC Adv., 2019, 9, 9410

Received 14th February 2019

Accepted 11th March 2019

DOI: 10.1039/c9ra01143a

rsc.li/rsc-advances

\section{CuaCo-MOFs as a novel catalyst of peroxymonosulfate for the efficient removal of methylene blue}

\begin{abstract}
Huanxuan Li, (D) *ab Shaodan $\mathrm{Xu}^{\mathrm{a}}{ }^{\mathrm{J}} \mathrm{Jia} \mathrm{Du},{ }^{\mathrm{a}}$ Junhong Tang ${ }^{\star a}$ and Qingwei Zhou ${ }^{\mathrm{a}}$
In this study, for the first time, we describe the single step synthesis of a Cu particle-doped cobalt-based metal-organic framework (CuaCo-MOF) using a hydrothermal method. The as-prepared materials were characterized by powder X-ray diffraction, Fourier transform infrared spectroscopy, scanning electron microscopy-energy disperse spectroscopy, thermogravimetry, and X-ray photoelectron spectroscopy, which confirmed the incorporation of zero-valent copper on the surface of the Co-MOFs. The heterogeneous catalytic activity of CuaCo-MOFs was tested to activate peroxymonosulfate (PMS) for the removal of methylene blue (MB). The ratio of $n(\mathrm{Cu}) / n(\mathrm{Co})$ in the Cu(Co-MOFs showed a strong impact on the catalytic activity of the CuaCo-MOFs, whereas a $n(\mathrm{Cu}) / n(\mathrm{Co})$ of $1: 1$ exhibited the best catalytic performance and obtained $100 \%$ MB removal within 30 min. The effects of initial $\mathrm{pH}$, reaction temperature, PMS concentration, and catalyst dosages were investigated in this study. The stability and reusability of the CuCCo-MOFs were also investigated. The results showed a low decline in the MB removal with the increase in cycle numbers, whereas $100 \%$ MB was removed by prolonging the reaction time. Heterogeneous reactions taking place in the pores and surface of the Cu(Co-MOFs played an important role in the generation of the sulfate radicals $\left(\mathrm{SO}_{4}{ }^{-}\right)$and hydroxyl radicals $(\cdot \mathrm{OH})$ that were the primary reactive species responsible for MB degradation.
\end{abstract}

\section{Introduction}

Dye wastewater has become one of the great focus points of investigation due to the considerable usage of dyes that considerably pollute the environment and cause severe consequences. At present, more than 100000 commercial dyes exist and over 1 million tons of dyes are manufactured each year, ${ }^{1}$ which are toxic and harmful to the environment and humans. ${ }^{2}$ Therefore, it is of vital importance to treat the water polluted with organic dyes before it is released into the environment. Many technologies such as physical adsorption, ${ }^{3,4}$ microbial degradation, ${ }^{5}$ chemical oxidation, ${ }^{6,7}$ ultrasonication and membrane methods have been used for the removal of such pollutants. However, the organic dyes are just transported from one media to another by activated carbon or other porous materials via adsorption, and they are therefore not completely eliminated from the environment. The microbial degradation process is time-consuming and inefficient because most organic dyes are non-biodegradable due to their complex structure and stability. ${ }^{8}$ For the ultrasonic and

${ }^{a}$ Hangzhou Dianzi University, College Materials \& Environmental Engineering, Hangzhou 310018, Zhejiang, PR China. E-mail: hxlee@hdu.edu.cn; tangjunhong@ hdu.edu.cn

${ }^{b}$ The Key Lab of Pollution Control and Ecosystem Restoration in Industry Clusters, Ministry of Education, South China University of Technology, Guangzhou Higher Education Mega Center, Guangzhou 510006, PR China membrane methods, the results are inconsistent and these methods are still at preliminary stages; ${ }^{9}$ in addition, these methods are expensive.

Sulfate radical $\left(\mathrm{SO}_{4}{ }^{-}\right)$-based advanced oxidation processes (SR-AOPs) are known to be the most effective method to oxidize the bio-recalcitrant organic pollutants. ${ }^{10-12}$ SR-AOPs are a kind of technology for the in situ generation of the $\mathrm{SO}_{4}{ }^{-{ }^{-}}$radical. Moreover, other reactive free radicals with high oxidation potential such as hydroxyl radicals $(\cdot \mathrm{OH})$ and superoxide radicals $\left(\cdot \mathrm{O}_{2}{ }^{-}\right)$could be produced by changing the reaction conditions. ${ }^{13-15}$ Peroxydisulfate (PDS, $\mathrm{S}_{2} \mathrm{O}_{8}{ }^{2-}$ ) and peroxymonosulfate (PMS, $\mathrm{HSO}_{5}{ }^{-}$) are the common precursors of the $\mathrm{SO}_{4}{ }^{--}$radical, but they are very stable at room temperature and unable to degrade organic pollutants. Therefore, extra energy and/or catalysts are needed to activate them for the generation of free radicals. ${ }^{16,17}$ Compared to the other transition metal ions, $\mathrm{Fe}^{2+}$ is the most efficient transition metal for the activation of PDS, while $\mathrm{Co}^{2+}$ is the best catalyst for the decomposition of PMS to generate $\mathrm{SO}_{4}{ }^{\cdot-}$ radicals. ${ }^{13}$ In addition, $\mathrm{Ag}(\mathrm{I})$ also shows the best catalytic performance toward activating PDS. ${ }^{13}$ However, $\mathrm{Fe}^{2+}$ would react with $\mathrm{SO}_{4}{ }^{-}$- and result in a decline in the pollutant removal efficiency. ${ }^{18}$ The widespread use of $\mathrm{Co}^{2+}$ may not be conducive to the human health and the quality of the environment. ${ }^{19}$ As for $\mathrm{Ag}(\mathrm{I})$, the cost is very high and it may be unrealistic to use in industry. Thus, alternative catalysts with high efficiency are urgently needed. 
Metal-organic frameworks (MOFs), a new kind of material with a periodic structure, are constructed from inorganic metal nodes and organic ligands with a topological structure. ${ }^{\mathbf{2 0 - 2 2}}$ The promising characteristics of highly ordered structure, large specific surface areas and tunable structural features render MOFs suitable for its applications in many fields, including separation, ${ }^{23}$ gas storage,${ }^{24}$ drug delivery ${ }^{25}$ and catalysis. ${ }^{26}$ As the "nodes" of the MOFs, metal ions are expected to be potential heterogeneous activators of PDS or PMS. Gao et al. ${ }^{27}$ investigated the catalytic performance of MIL-53 as heterogeneous photocatalysts of PDS under visible LED light, their results demonstrated that the accelerated photocatalytic degradation of organic pollutants was obtained in the presence of PDS. Febased metal-organic frameworks including MIL-101(Fe), MIL$100(\mathrm{Fe}), \mathrm{MIL}-53(\mathrm{Fe})$, and MIL-88B(Fe) were examined as the activators of PDS to remove acid orange 7 (AO7) from an aqueous solution, but the degradation efficiency was low because of the weak reaction activity between Fe(III) and PDS. ${ }^{28}$ Apparently, many MOFs materials can only be used in light photocatalysis because of their wide bandgap. ${ }^{7,29,30}$ In our previous study, the catalytic activity of the Co-based MOFs $\left(\mathrm{Co}_{3}(\mathrm{BTC})_{2} \cdot 12 \mathrm{H}_{2} \mathrm{O}\right)$ was investigated as the activator of PMS for the degradation of dibutyl phthalate (DBP) in water, and it was found that the water stability of $\mathrm{Co}_{3}(\mathrm{BTC})_{2} \cdot 12 \mathrm{H}_{2} \mathrm{O}$ needed to improve. $^{31}$ Another MOFs, Cu-BTC $\left(\mathrm{Cu}_{3}(\mathrm{BTC})_{2} \cdot 12 \mathrm{H}_{2} \mathrm{O}\right)$ was stable in water, but its catalytic performance for the decomposition of PDS was weak. ${ }^{32}$ Therefore, it is a great challenge to increase the water stability and catalytic performance of MOFs for further enhancement of organic pollutants degradation.

Inspired by the above results, we tried to synthesize a bimetallic-organic framework combination with $\mathrm{Cu}$ and $\mathrm{Co}$, with the purpose of improving the water stability and catalytic performance of MOFs. In this study, we expected that the addition of $\mathrm{Cu}^{2+}$ and $\mathrm{Co}^{2+}$ into the reaction vessel would result in a bimetallic $\mathrm{Cu}-\mathrm{Co}-\mathrm{MOF}$ with better catalytic performances. However, surprisingly, we observed very few $\mathrm{Cu}^{2+}$ ions replace the $\mathrm{Co}^{2+}$ ions in the Co-MOF structure, most of them translated to zerovalent copper and grew on the surface of Co-MOF. The catalytic activity of the as-prepared materials (denoted as Cu@Co-MOFs) as the catalysts of PMS for the generation of $\mathrm{SO}_{4}{ }^{-}{ }^{-}$radicals was tested. In addition, cyclic tests for the pollutant degradation efficiency were also conducted to evaluate the materials' stability. The as-prepared Cu@Co-MOFs composites offer an excellent catalytic performance for the MB removal from water, making it a perfect candidate for heterogeneous catalysis.

\section{Materials and methods}

\subsection{Materials}

Unless otherwise specified, all the chemicals and reagents were of reagent grade and used without further purification. Terephthalic acid (BDC), cobalt nitrate hexahydrate $\left(\mathrm{Co}\left(\mathrm{NO}_{3}\right)_{2}\right.$ $\left.\cdot 6 \mathrm{H}_{2} \mathrm{O}\right)$, cupric nitrate trihydrate $\left(\mathrm{Cu}\left(\mathrm{NO}_{3}\right)_{2} \cdot 3 \mathrm{H}_{2} \mathrm{O}\right)$ and methylene blue ( $\mathrm{MB}, \geq 90 \%$, HPLC) were purchased from Maclean reagent Co., Ltd (Shanghai, China). Sodium persulfate $\left(\mathrm{Na}_{2} \mathrm{~S}_{2} \mathrm{O}_{8}, 99.0 \%\right)$, potassium monopersulfate triple salt $\left(\mathrm{KHSO}_{5} \cdot 0.5 \mathrm{KHSO}_{4} \cdot 0.5 \mathrm{~K}_{2} \mathrm{SO}_{4}\right.$ ) (purity $>47 \% \mathrm{KHSO}_{5}$ basis), $N, N$ - dimethyl formamide (DMF) and all other chemicals such as ethanol (EtOH), tert-butyl alcohol (TBA), sodium hydroxide $(\mathrm{NaOH})$ and sulfuric acid $\left(\mathrm{H}_{2} \mathrm{SO}_{4}\right)$ were purchased from Sinopharm Chemical Reagent Co., Ltd (Beijing, China).

\subsection{Preparation of Cu@Co-MOFs}

The Cu@Co-MOFs was prepared via a one-step hydrothermal method. Briefly, cupric nitrate trihydrate ( $6 \mathrm{mM}, 1.449 \mathrm{~g})$, cobalt nitrate hexahydrate ( $6 \mathrm{mM}, 1.946 \mathrm{~g})$, and terephthalic acid $(12 \mathrm{mM}, 1.994 \mathrm{~g})$ were dissolved in $60 \mathrm{~mL}$ of $N, N$-dimethyl formamide (DMF). Then, the mixed solution was stirred for 30 min under vigorous magnetic stirring at room temperature, followed by transferring the solution into a Teflon-lined stainless steel autoclave with a volume capacity of $100 \mathrm{~mL}$, and then $0.8 \mathrm{~mL}$ of hydrofluoric acid was added to the solution. The resulting mixture was heated up to $150{ }^{\circ} \mathrm{C}$ for $72 \mathrm{~h}$ in an oven. After the heat treatment, the autoclave was allowed to cool naturally to room temperature, and the collected products were refined through centrifugation and rinsed with DMF $(3 \times 20$ $\mathrm{mL})$ along with ethanol $(3 \times 20 \mathrm{~mL})$ and deionized water $(3 \times 50$ $\mathrm{mL}$ ) alternatively, and then dried in vacuum at $100{ }^{\circ} \mathrm{C}$ for $10 \mathrm{~h}$.

To assess the effect of molar ratios (including the molar ratio of $\left(\mathrm{Co}^{2+}+\mathrm{Cu}^{2+}\right):$ BDC and molar ratio of $\left.\mathrm{Co}^{2+}: \mathrm{Cu}^{2+}\right)$ on the structure and properties of Cu@Co-MOFs catalysts, different samples were prepared by varying the concentration of the two metal ions and BDC, the specific description is presented in Table 1.

\subsection{Characterization}

The morphology of the as-synthesized Cu@Co-MOFs was investigated using a thermal field emission scanning electron microscope (FESEM, Quanta 200, Holland), which was linked to the EDS/INCA 350 (energy dispersive X-ray analyser). Before testing, the sample surface was gold-coated. Powder X-ray diffraction (PXRD) patterns of the Cu@Co-MOFs were recorded on an X-ray diffractometer D8 Advance X-ray Diffraction system with a scan speed of $2^{\circ} \min ^{-1}$ and a step size of $0.02^{\circ}$ at the range of $5-80^{\circ}$. Fourier transform infrared (FTIR) spectra were recorded with a $\mathrm{KBr}$ disk containing the powder sample using an FTIR spectrometer (Nicolet Magna 550) in the range of 2000-400 $\mathrm{cm}^{-1}$. Photoelectron spectroscopy (XPS) was performed using an X-ray photoelectron spectroscopy (ESCA) spectrometer with a monochromatized Al-K X-ray source. The Brunauer-Emmett-Teller specific surface area was determined through nitrogen adsorption/desorption experiments conducted using a NOVA 2000e gas adsorption analyzer (Quantachrome Corp.). Prior to the analysis, the samples were degassed at $150{ }^{\circ} \mathrm{C}$ for $1 \mathrm{~h}$. The thermal stability of the $\mathrm{Cu@Co-MOFs} \mathrm{was}$ determined by DSC-TGA analysis (Q1000DSC + LNCS + FACS Q600SDT) with a heating rate of $10^{\circ} \mathrm{C} \mathrm{min}^{-1}$ in flowing nitrogen gas.

\subsection{Evaluation of $\mathrm{Cu}$ (C)-MOFs reactivity as a catalyst}

Catalytic degradation experiments were performed in a $250 \mathrm{~mL}$ Erlenmeyer flask at $120 \mathrm{rpm}$ in a rotary shaker (SHZ-C, Shanghai, China). A certain amount of PMS and MB were 
Table 1 Synthetic parameters of the Cu@Co-MOFs samples

\begin{tabular}{|c|c|c|c|c|c|}
\hline Sample & $n\left(\mathrm{Co}\left(\mathrm{NO}_{3}\right)_{2} \cdot 6 \mathrm{H}_{2} \mathrm{O}\right) / \mathrm{mM}$ & $n\left(\mathrm{Cu}\left(\mathrm{NO}_{3}\right)_{2} \cdot 3 \mathrm{H}_{2} \mathrm{O}\right) / \mathrm{mM}$ & $n(\mathrm{BDC}) / \mathrm{mM}$ & $\mathrm{Co}^{2+} / \mathrm{Cu}^{2+}$ & $\begin{array}{l}\left(\mathrm{Cu}^{2+}+\right. \\
\left.\mathrm{Co}^{2+}\right) / \mathrm{BDC}\end{array}$ \\
\hline Cu@Co-MOFs-1 & 2.4 & 9.6 & 12 & $1: 4$ & $1: 1$ \\
\hline Cu@Co-MOFs-3 & 6 & 6 & 12 & $1: 1$ & $1: 1$ \\
\hline Cu@Co-MOFs-4 & 7.2 & 4.8 & 12 & $3: 2$ & $1: 1$ \\
\hline Cu@Co-MOFs-5 & 9.6 & 2.4 & 12 & $4: 1$ & $1: 1$ \\
\hline
\end{tabular}

added into a final volume of $100 \mathrm{~mL}$ deionized water, giving initial concentrations of MB and PMS of $0.2 \mathrm{mM}$ and $4.0 \mathrm{mM}$, respectively. The degradation reaction was initiated after adding the catalyst. Samples were withdrawn at the predetermined time intervals and quenched by ethanol before analysis. ${ }^{15}$ The initial $\mathrm{pH}$ of the reactions was adjusted by $\mathrm{H}_{2} \mathrm{SO}_{4}(1.0 \mathrm{M})$ or $\mathrm{NaOH}(1.0 \mathrm{M})$. For the successive recycling reaction, the used catalyst was separated by centrifugal separation after the completion of the reaction and washed with water for 4 times. Then, the catalyst was dispersed in a $100 \mathrm{~mL}$ solution containing the same concentration of MB and PMS. All experiments were performed in triplicates.

\subsection{Analytical methods}

The MB concentration during the reaction was analyzed by measuring the absorbance in the visible spectra at the characteristic wavelength of $\mathrm{MB}\left(\lambda_{\max }=666 \mathrm{~nm}\right)$ using a UV-Vis spectrophotometer (UV2301 II, Shanghai, China). The concentration of PMS was determined by spectrophotometric determination with iodometric titration..$^{33}$ The leaching metal ions (including copper ion and cobalt ion) in reaction solutions and metallic elements in $\mathrm{Cu@Co-MOFs} \mathrm{structure} \mathrm{were} \mathrm{measured}$ using an inductively coupled plasma-atomic emission spectrometer (ICP-AES, PE OPTIMA 2100DV). The mineralization of MB was established on the basis of the total organic carbon (TOC) content, performed using a TOC analyzer (Shimadzu) after the sample was quenched by $2 \mathrm{M}$ sodium thiosulfate. The $\mathrm{pH}$ was monitored with a pH meter (Shanghai LeiCi PHS-25) equipped with a $\mathrm{pH}$ electrode.

\section{Results and discussion}

\subsection{The crystallization and morphological analyses of the Cu@Co-MOFs}

X-ray diffraction (XRD) was used for the characterization of the Cu@Co-MOFs-3 structure. As shown in Fig. 1A, the clear and sharp diffraction peaks at $2 \theta=9.0^{\circ}, 11.0^{\circ}, 14.1^{\circ}, 17.8^{\circ}, 19.2^{\circ}$, $21.0^{\circ}, 22.0^{\circ}, 23.9^{\circ}, 29.5^{\circ}, 30.8^{\circ}, 33.1^{\circ}, 34.5^{\circ}, 40.3^{\circ}$ are ascribed to the patterns of the Co-MOFs, indicating a good crystallinity of the as-prepared material. Interestingly, the diffraction peaks at $43.4^{\circ}, 50.4^{\circ}$ and $74.1^{\circ}$ can be indexed to the indices (200), (220), and (440) of zero-valent copper. ${ }^{34}$ This indicated that a part of cupric nitrate trihydrate was reduced to zero-valent copper by DMF at high temperature. In order to determine whether the organic compounds were present, FT-IR spectroscopy was performed to identify the characteristic functional groups associated with $\mathrm{Cu@Co-MOFs-3.} \mathrm{As} \mathrm{displayed} \mathrm{in} \mathrm{Fig.} \mathrm{1B,} \mathrm{the} \mathrm{FT-IR}$ spectrum of $\mathrm{Cu} @ \mathrm{Co}-\mathrm{MOFs}-3$ showed characteristic peaks at $1650.1 \mathrm{~cm}^{-1}, \quad 1576.7 \mathrm{~cm}^{-1}, \quad 1398.1 \mathrm{~cm}^{-1}, 815.0 \mathrm{~cm}^{-1}$, $757.5 \mathrm{~cm}^{-1}, 625.4 \mathrm{~cm}^{-1}$, and $521.5 \mathrm{~cm}^{-1}$. In detail, the bands located at $1650 \mathrm{~cm}^{-1}$ was associated with the stretching vibrations of the $\nu_{\text {as }}(\mathrm{C}=\mathrm{O}){ }^{31}$ The strong band of FTIR at $1398.1 \mathrm{~cm}^{-1}$ was ascribed to the asymmetric stretching $\left(\nu_{\text {as }}(\mathrm{C}-\mathrm{O})\right)$, while another strong bank at $1576.7 \mathrm{~cm}^{-1}$ was due to the presence of symmetric $\left(\nu_{\mathrm{s}}(\mathrm{C}-\mathrm{O})\right)$ vibrations, confirming the presence of the dicarboxylate linker within the frameworks. ${ }^{27}$ The peak at $757.5 \mathrm{~cm}^{-1}$ reflected the presence of the $\mathrm{C}-\mathrm{H}$ bending vibrations of benzene. The adsorption bands at $625.4 \mathrm{~cm}^{-1}$ and $521.5 \mathrm{~cm}^{-1}$ may be a characteristic of the Co-O stretching vibration in the $\mathrm{Cu} @ \mathrm{Co}-\mathrm{MOFs}-3$. The TGA results indicated that the Cu@Co-MOFs-3 was stable up to over $350^{\circ} \mathrm{C}$, indicating that the as-prepared $\mathrm{Cu} @ \mathrm{Co}-\mathrm{MOFs}-3$ exhibited good thermal stability. Besides, the organic bridge of BDC was more stable after combination with copper and cobalt.

To validate the chemical constitution of the as-synthesized Cu@Co-MOFs-3, the Cu@Co-MOFs-3 sample was further studied via XPS analysis. A wide survey scan of XPS spectra was taken in the range $0-1400 \mathrm{eV}$, as shown in Fig. 2A. It can be seen that the Cu@Co-MOFs-3 mainly contained the elements C, O, $\mathrm{Co}$, and $\mathrm{Cu}$. In addition, the peaks of $\mathrm{Co}$ and $\mathrm{Cu}$ exhibit a similar peak area, which had confirmed that both the metal ions of $\mathrm{Co}$ and $\mathrm{Cu}$ had successfully participated in the construction of the as-prepared materials. In order to gain insights into the chemical state of $\mathrm{Cu}$ and $\mathrm{Co}$ in the composites, we had measured the $\mathrm{Cu} 2 \mathrm{p}_{3 / 2}$ and $\mathrm{Co} 2 \mathrm{p}_{3 / 2}$ spectra, which are displayed in Fig. 2B and C. In Fig. 2B, the 2p3/2 peak of Cu splits into two peaks at $932.5 \mathrm{eV}$ and $935.0 \mathrm{eV}$ after fitting along with the satellite peak at $942.8 \mathrm{eV}$. The peak located at $932.5 \mathrm{eV}$ was attributed to the zero-valent copper $\mathrm{Cu}(0),{ }^{35}$ revealing that the surface copper was present in the $\mathrm{Cu}(0)$ state. The peak located at a binding energy of $935.0 \mathrm{eV}$ was assigned to $\mathrm{Cu}$ (II). In addition, the relative area of the $\mathrm{Cu}(\mathrm{II})$ spectrum was $35.4 \%$, while the relative area of the $\mathrm{Cu}(0)$ spectrum was $64.6 \%$. This result indicated that most of the cupric nitrate trihydrate translated to zero-valent copper and a very small amount of cupric nitrate trihydrate was incorporated into Co-MOFs. As shown in Fig. 2C, after the peak fitting, the peak appeared at a binding energy of $782.0 \mathrm{eV}$ along with a satellite peak $(786.9 \mathrm{eV})$ that was assigned to Co(II). ${ }^{36}$ In Fig. 2D, the wide and asymmetric O 1s XPS peak 

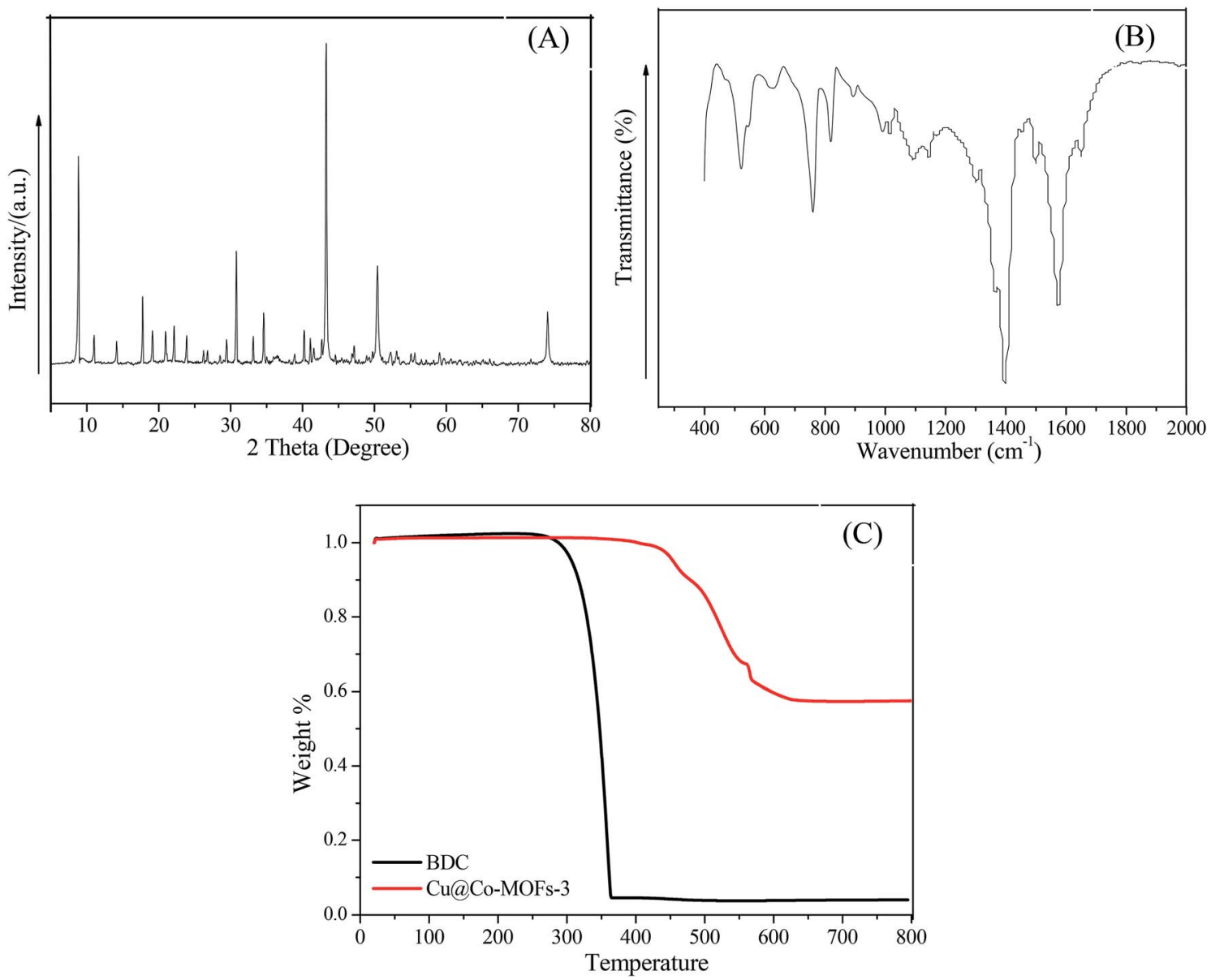

Fig. 1 PXRD pattern (A), FT-IR spectra (B) and TGA (C) of the as-synthesized Cu(CCo-MOFs-3.

proved that there were more than one chemical states. The lower binding energy peak at $531.3 \mathrm{eV}$ was ascribed to the Co-O bands. ${ }^{37}$ The other peak located at $532.2 \mathrm{eV}$ was attributed to the carboxylate groups of the BDC linkers $(\mathrm{O}-\mathrm{C}=\mathrm{O})$. These results together with XRD and FT-IR analyses indicate the $\mathrm{Cu}$ @CoMOFs-3 was synthesized successfully with a one-step hydrothermal method.

The morphology of $\mathrm{Cu}$ @CuCo-MOFs-3 was examined using SEM, as presented in Fig. 3. The as-prepared materials present a regular bounded polyhedron structure with an average size of ca. 15-20 $\mu \mathrm{m}$. Apparently, small particles grew on the surface of the Co-MOFs. In order to confirm the composition of the particles, the as-prepared materials were investigated by EDS elemental mapping analysis. The yellow dots represented the $\mathrm{Cu}$ element, and the particles on the surface were confirmed to be copper. Moreover, the other elements Co, C, and O present in the sample are marked with blue, red, and green dots, respectively, and they were uniformly distributed in the as-prepared materials. Using the SEM combined with EDS mapping analysis, it was further confirmed that $\mathrm{Cu}$ particles were successfully grown on the surface of Co-MOFs. The permanent porosity of the Cu@CoMOFs-3 was verified by Brunauer-Emmett-Teller (BET) analysis, which indicated that the surface area and micropore volume were $11.72 \mathrm{~m}^{2} \mathrm{~g}^{-1}$ and $0.038 \mathrm{~cm} \mathrm{~g}^{-1}$, respectively.
Elemental analysis by ICP-MS indicated that copper and cobalt loading of $0.087 \mathrm{mmol} \mathrm{g}^{-1}$ and $0.064 \mathrm{mmol} \mathrm{g}^{-1}$, respectively, for $\mathrm{Cu} @ \mathrm{Co}-\mathrm{MOFs}-3$, indicating that both copper and cobalt coexisted in the as-prepared materials. The atomic ratios of $\mathrm{Cu} / \mathrm{Co}$ in the $\mathrm{Cu} @ \mathrm{Co}-\mathrm{MOFs}-3$ were found to be 1.36 , which was 1.0 in the as-synthesized reactions.

\subsection{Effects of preparation condition}

Fig. 4 presents the catalytic activity of $\mathrm{Cu@Co-MOFs} \mathrm{obtained}$ from different preparation conditions. It was clear that all catalysts showed an excellent catalytic performance for the decomposition of PMS, resulting in more than $70 \%$ of the $\mathrm{MB}$ removal rate. However, for PDS, the catalytic activity of the catalysts was much lower. In Fig. 4A, it was remarkable that the catalyst (Cu@Co-MOFs-6) showed the best catalytic performance on PDS when the molar ratio of the [metal ions]/[BDC] was set to $2 / 3$ in the preparation procedure. However, the catalyst obtained with a molar ratio of 1/1 (Cu@Co-MOFs-3) showed the highest catalytic activity on PMS and resulted in the $100 \%$ removal of $\mathrm{MB}$, as shown in Fig. 4B. Apparently, the $\mathrm{MB}$ removal rate seemed to be well related to the $n(\mathrm{Co}) / n(\mathrm{Cu})$ ratios of the materials in the preparation procedure. With the presence of PDS, the MB removal decreased with an increase in 

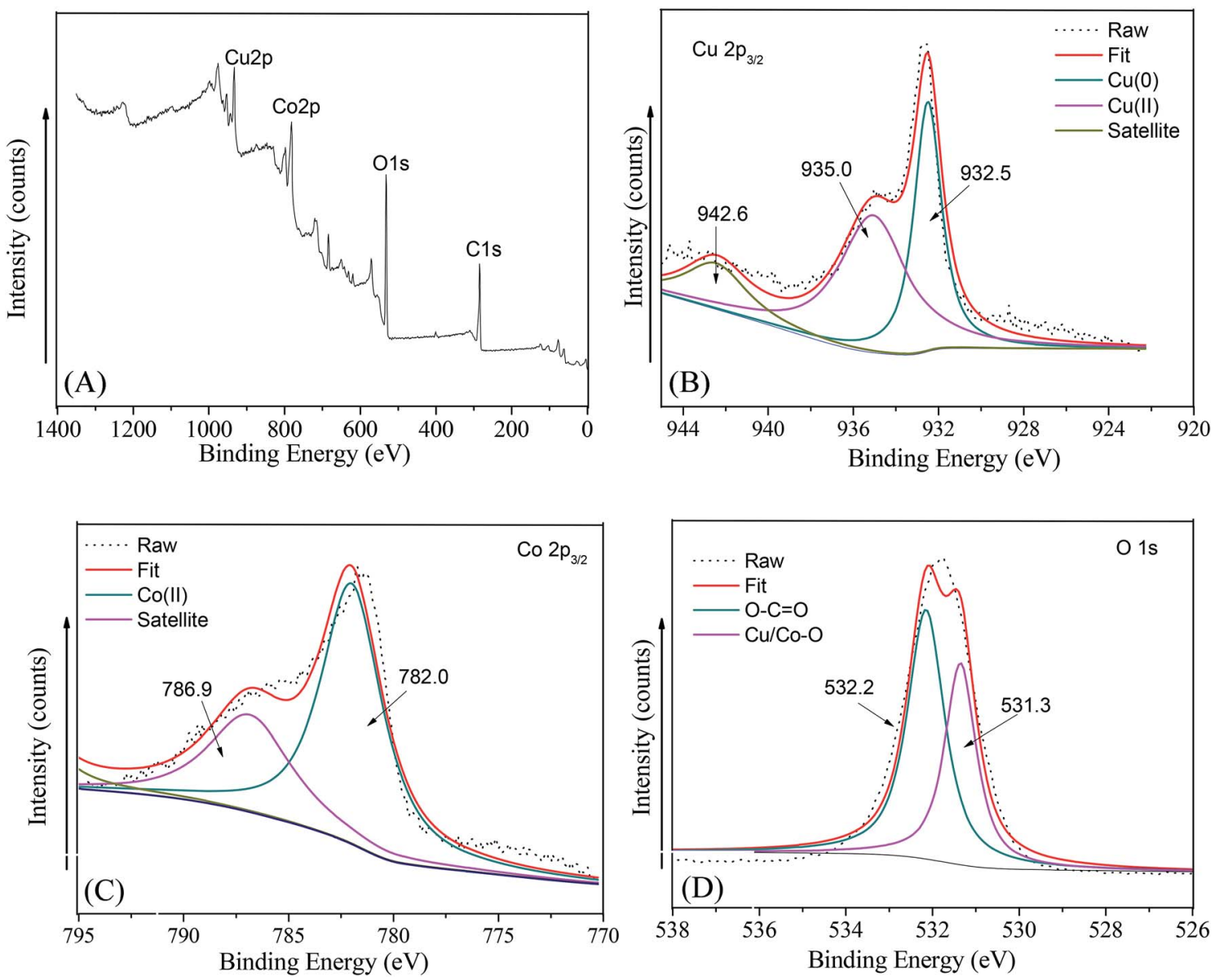

Fig. 2 The XPS spectra of the as-prepared Cu/Co-MOFs-3: (A) survey, (B) Cu 2p $p_{3 / 2}$, (C) Co 2p $p_{3 / 2}$, (D) O $1 \mathrm{~s}$.

the $n(\mathrm{Co}) / n(\mathrm{Cu})$ ratio. Conversely, the $\mathrm{MB}$ removal increased when the $n(\mathrm{Co}) / n(\mathrm{Cu})$ ratios increased from $1 / 4$ to $3 / 2$ in the PMS solutions. Nevertheless, a further increase in the $n(\mathrm{Co}) / n(\mathrm{Cu})$ ratio resulted in a decrease in the $\mathrm{MB}$ removal rate when $n(\mathrm{Co}) /$ $n(\mathrm{Cu})$ exceeded $3 / 2$. This could be elucidated by the well-known scavenging effect of $\mathrm{SO}_{4}{ }^{--}$radical (eqn. (1) and (2)), resulting in the competitive reactions between $\mathrm{MB}$ and $\mathrm{SO}_{4}{ }^{--}$.

$$
\begin{gathered}
\mathrm{SO}_{4}{ }^{--}+\mathrm{SO}_{4}{ }^{--} \rightarrow 2 \mathrm{SO}_{4}{ }^{2-} \\
\mathrm{S}_{2} \mathrm{O}_{8}{ }^{2-}+\mathrm{SO}_{4}{ }^{--} \rightarrow \mathrm{SO}_{4}{ }^{2-}+\mathrm{S}_{2} \mathrm{O}_{8}{ }^{--}
\end{gathered}
$$

As a result, the MB removal rate in the $\mathrm{Cu} @ \mathrm{Co}-\mathrm{MOFs}-4 / \mathrm{PMS}$ system reached the highest, but $100 \%$ of MB was completely removed in both the $\mathrm{Cu@Co-MOFs-3/PMS} \mathrm{and} \mathrm{Cu@Co-MOFs-4/}$ PMS systems. Hence, considering the cobalt toxicity and reducing its usage amount, the subsequent experiments were conducted using $\mathrm{Cu} @ \mathrm{Co}-\mathrm{MOFs}-3$ as catalysts.

\subsection{Catalytic reactivity of Cu@Co-MOFs-3}

The catalytic performance of the $\mathrm{Cu@Co-MOFs-3} \mathrm{was} \mathrm{evaluated}$ by the $\mathrm{MB}$ removal efficiency and the mineralization rate of $\mathrm{MB}$, the results are present in Fig. 5. As a comparison, experiments were performed in different systems (see in Fig. 4). It can be clearly seen that less than $10 \%$ of $\mathrm{MB}$ was removed from the solution over $30 \mathrm{~min}$ in the control systems with only $\mathrm{Cu} @ \mathrm{Co}^{-}$ MOFs-3, revealing that this material showed a low adsorption performance on MB. With the addition of PDS to the $\mathrm{Cu} @ \mathrm{Co}$ MOFs-3/MB system, about $28 \%$ of MB was removed within 30 min, indicating that $\mathrm{Cu} @ \mathrm{Co}-\mathrm{MOFs}-3$ exhibited a considerably low catalytic activity for PDS. On the contrary, $100 \%$ of the MB removal rate was obtained under identical reaction conditions in the $\mathrm{Cu} @ \mathrm{Co}-\mathrm{MOFs}-3 / \mathrm{MB} / \mathrm{PMS}$ system. Although the TOC removal rate was only $12.4 \%$ within $30 \mathrm{~min}$, it reached $62.9 \%$ after $9.0 \mathrm{~h}$. This fact suggested that Cu@Co-MOFs-3 showed superior catalytic performances for the PMS oxidation of MB.

\subsection{Effects of $\mathrm{Cu} / \mathrm{Co}-\mathrm{MOFs}-3$ dosage and PMS concentration}

The effect of the $\mathrm{Cu} @ \mathrm{Co}$-MOFs-3 dosage on the MB removal rate was investigated with the aim to get further insight into the catalytic activity of $\mathrm{Cu} @ \mathrm{Co}-\mathrm{MOFs}-3$. As displayed in Fig. 6A, the MB removal rate increased evidently with an increase in the Cu@Co-MOFs-3 dosage from $30 \mathrm{mg} \mathrm{L}^{-1}$ to $200 \mathrm{mg} \mathrm{L}^{-1}$. It was noted that $0.2 \mathrm{mM}$ of $\mathrm{MB}$ was completely removed within $30 \mathrm{~min}$ when the dosage was increased to $100 \mathrm{mg} \mathrm{L}^{-1}$. Moreover, the final PMS consumption increased with an increase in the Cu@Co-MOFs-3 dosage (shown in Fig. 6B). The effect of the 

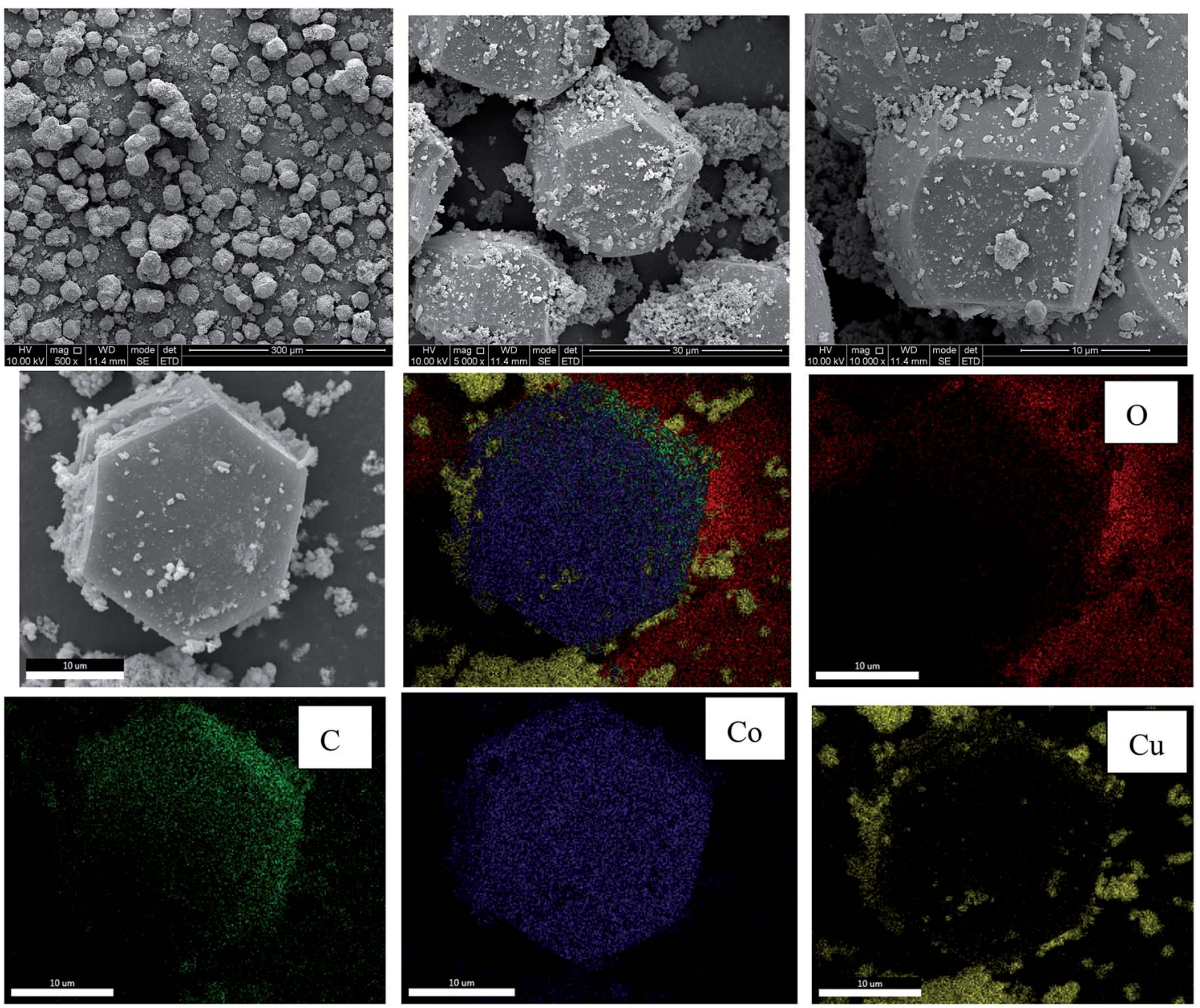

Fig. 3 SEM-EDS of as prepared Cu@Co-MOFs-3.

PMS dosage was also investigated, and the results are illustrated in Fig. 6C. It was observed that the MB removal efficiency increased evidently as the PMS concentration increased from $0.4 \mathrm{mM}$ to $2.0 \mathrm{mM}$. However, a further increase in the PMS concentration resulted in a decrease in the MB removal, which could be due to the scavenging effect. Moreover, it was concluded that $2.0 \mathrm{mM}$ of PMS was the optimal concentration for the MB removal in this system. These results further proved that the $\mathrm{Cu@Co-MOFs-3} \mathrm{exhibited} \mathrm{an} \mathrm{excellent} \mathrm{catalytic} \mathrm{activity}$ for the decomposition of PMS and generation of sulfate radicals.

\subsection{Effect of initial $\mathrm{pH}$ and temperature}

$\mathrm{pH}$ value is one of the main factors affecting the wastewater treatment using AOPs, hence, it is necessary to investigate the influence of the initial $\mathrm{pH}$ on the catalytic activity of $\mathrm{Cu} @ \mathrm{Co}-$ MOFs-3. The MB removal with an initial concentration $\left(C_{0}\right)$ of $0.2 \mathrm{mM}$ under different initial pH values is exhibited in Fig. 7A. It can be seen that the MB was completely removed within $30 \mathrm{~min}$ in the $\mathrm{pH}$ range of 3.0-11.0, indicating that the $\mathrm{Cu@Co-}$ MOFs-3 remained stable and showed an efficient catalytic activity over a wide $\mathrm{pH}$ range. Moreover, it was remarkable that the $\mathrm{MB}$ removal rate was highest at $\mathrm{pH} 110$. This might be attributed to the fact that the base could promote the PMS activation and the optimum initial $\mathrm{pH}$ is about 11 for PMS activation..$^{38}$ The effect of reaction temperature on the $\mathrm{MB}$ removal is illustrated in Fig. $7 \mathrm{C}$, and it appears that the temperature has a weak influence on the MB removal rate, as $\mathrm{MB}$ was completely removed in the temperature of $25-60{ }^{\circ} \mathrm{C}$. It is noteworthy that the first-order kinetic constants of $\mathrm{MB}$ increased evidently when the reaction temperature increased from $25{ }^{\circ} \mathrm{C}$ to $60{ }^{\circ} \mathrm{C}$.

\subsection{Stability of the $\mathrm{Cu@Co-MOFs-3}$ and removal mechanism of MB}

In order to evaluate the stability of Cu@Co-MOFs-3, four recycling runs using the $\mathrm{Cu@Co-MOFs-3} \mathrm{were} \mathrm{performed} \mathrm{under} \mathrm{the}$ identical reaction conditions. As shown in Fig. 8A, the removal efficiency of $\mathrm{MB}$ showed a little decrease compared with the previous runs, where $96.4 \%, 94.0 \%$ and $89.6 \%$ of MB were removed within $30 \mathrm{~min}$ in the $2^{\text {nd }}, 3^{\text {rd }}$, and $4^{\text {th }}$ runs, respectively. However, the MB was completely removed when the reaction time was prolonged, indicating that the $\mathrm{Cu} @ \mathrm{Co}-\mathrm{MOFs}-3$ processed good stability and long lifetime. The slight decrease in the MB removal rate can be attributed to the negligible loss of $\mathrm{Cu} @ \mathrm{Co}-\mathrm{MOFs}-3$, and the decay of the active catalytic sites 

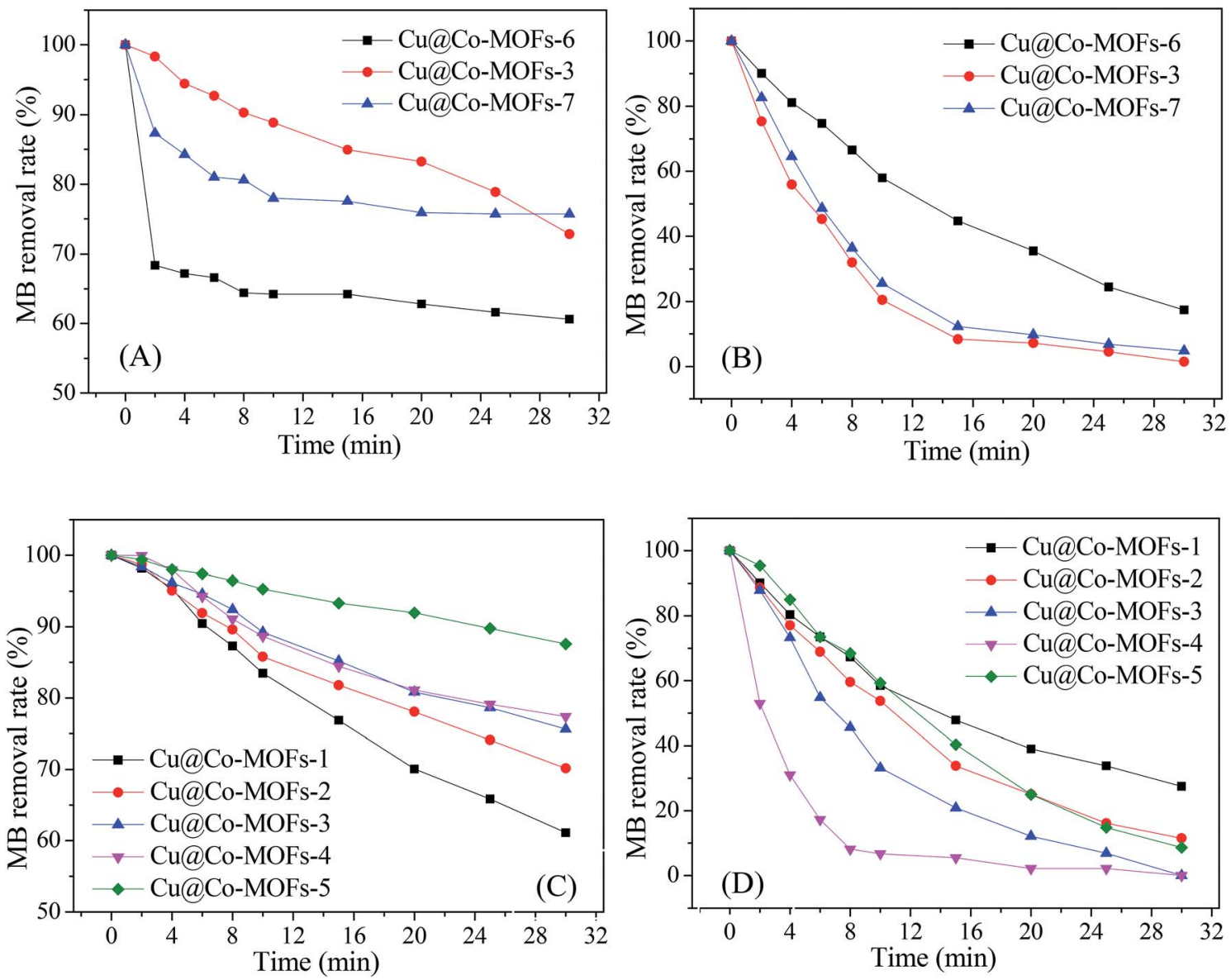

Fig. 4 (A) Effect of the molar ratio of [metal ions]/[BDC] on the MB removal rate in the presence of PDS; (B) effect of the molar ratio of [metal ions]/[BDC] on the MB removal rate in the presence of PMS; $(C)$ effect of the molar ratio of $n(\mathrm{Co}) / n(\mathrm{Cu})$ on the MB removal rate in the presence of PDS; (D) effect of the molar ratio of $n(\mathrm{Co}) / n(\mathrm{Cu})$ on the MB removal rate in the presence of PMS. Experiment condition: PDS $=2.0 \mathrm{mM}$, PMS $=$ $2.0 \mathrm{mM}, \mathrm{MB}=0.2 \mathrm{mM}$, catalyst $=0.1 \mathrm{~g} \mathrm{~L}^{-1}, T=25^{\circ} \mathrm{C}$.

caused by the small amounts of leached cobalt and copper from the catalyst surface. According to the ICP-MS, the concentration of the leached cobalt was $3.89 \mathrm{mg} \mathrm{L}^{-1}$ at $\mathrm{pH} 2.75$, which was higher than the environmental quality standards for surface water (GB 3838-2002) (less than $1.0 \mathrm{mg} \mathrm{\textrm {L } ^ { - 1 }}$ ). ${ }^{39}$ However, approximately $0.89 \mathrm{mg} \mathrm{L}^{-1}$ cobalt was leached into the solution when the $\mathrm{pH}$ was set to 7.0 , where $100 \%$ of the $\mathrm{MB}$ removal rate was observed (see in Fig. 6A).
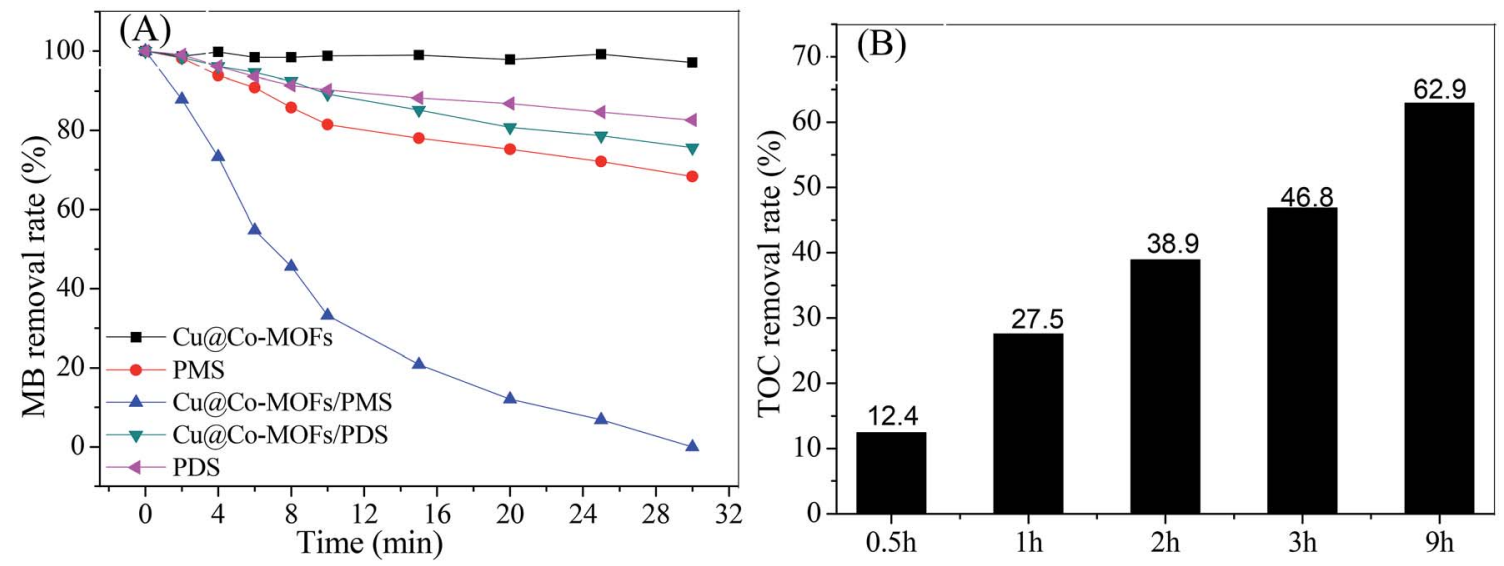

Fig. 5 (A) The degradation of $M B$ versus time in different systems and experimental condition: $P M S=2 m M ; P D S=2 m M, M B=0.2 m M$; CuaCo-MOFs- $3=0.1 \mathrm{~g} \mathrm{~L}^{-1}, T=25^{\circ} \mathrm{C}$; (B) the TOC removal rate versus time, experiment condition: $\mathrm{PMS}=4 \mathrm{mM}, \mathrm{MB}=0.2 \mathrm{mM}, \mathrm{Cu}$ (aCo-MOFs$3=0.2 \mathrm{~g} \mathrm{~L}^{-1}, T=25^{\circ} \mathrm{C}$. 

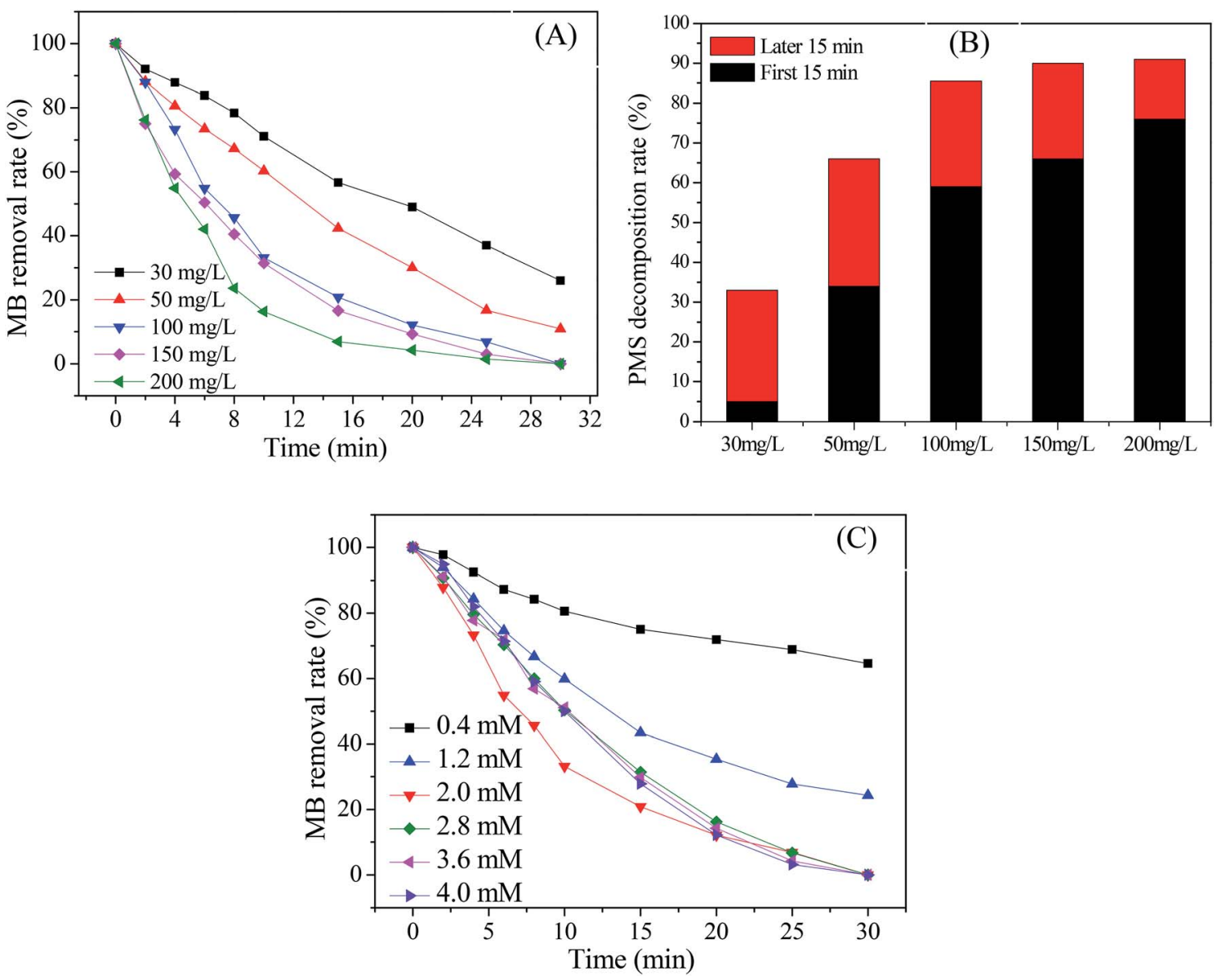

Fig. 6 (A) Effect of the catalyst dosage on the MB removal efficiency; (B) effect of the catalyst dosage on the PMS decomposition; (C) effect of the PMS concentration on the MB removal efficiency. Experiment condition: $\mathrm{MB}=0.2 \mathrm{mM}, \mathrm{PMS}=2 \mathrm{mM}$ (for $\mathrm{A}$ and $\mathrm{B}$ ), Cu(CO-MOFs-3 $=0.1 \mathrm{~g}$ $\mathrm{L}^{-1}$ (only for $\mathrm{C}$ ), $T=25^{\circ} \mathrm{C}$.

To gain insight into the pollutants removal mechanism, the scavenging experiments were investigated. Tertiary butanol (TBA) and ethanol (EtOH) are good candidates for quenching free radicals, including $\mathrm{SO}_{4}{ }^{-}$and $\cdot \mathrm{OH}$. As expected, both TBA and EtOH exerted an inhibiting effect on the MB removal rates, as shown in Fig. 8B. The MB removal rates decreased with an increase in the concentration of TBA and EtOH. This fact indicated that $\mathrm{SO}_{4}{ }^{-}$or ${ }^{\circ} \mathrm{OH}$ radical was the primary reactive species responsible for the removal of MB. Moreover, it was remarkable that the presence of EtOH led to a greater degree of inhibition than that of TBA, revealing the existence of $\mathrm{SO}_{4}{ }^{-}$. According to previous studies, ${ }^{40}$ pollutant degradation rates were inhibited by less than $10 \%$ by TBA if only $\mathrm{SO}_{4}{ }^{\cdot-}$ was generated for the oxidation of pollutants. The first-order kinetic constants of $\mathrm{MB}$ were inhibited by $24.7 \%$ and $41.3 \%$ when the molar ratio of TBA : MB were $500: 1$ and $1000: 1$, which indicated the presence of ${ }^{\circ} \mathrm{OH}$.

The excellent activity of $\mathrm{Cu@Co-MOFs-3} \mathrm{for} \mathrm{the} \mathrm{activation} \mathrm{of}$ PMS to generate $\mathrm{SO}_{4}{ }^{-}$and ${ }^{\circ} \mathrm{OH}$ radicals can be understood based on the synergistic behaviour of Co-MOFs-3 and zerovalent copper. According to the above-mentioned results, the heterogeneous catalytic reaction took place in the pores and the surface of $\mathrm{Cu} @$ Co-MOFs-3 while the homogeneous reaction took place in water solutions, which resulted in the generation of $\mathrm{SO}_{4}{ }^{\cdot-}$ and ${ }^{\circ} \mathrm{OH}$ radicals. However, the heterogeneous reaction played an important role in the generation of $\mathrm{SO}_{4}{ }^{-{ }^{-}}$and ${ }^{\circ} \mathrm{OH}$ radicals due to the low leaching concentration of $\mathrm{Co}^{2+}$ and $\mathrm{Cu}^{2+}$. The overall heterogeneous process of the MB oxidation underwent some necessary elementary steps like PMS adsorption, free radical generation, $\mathrm{MB}$ adsorption and transformation into intermediates, and eventually the oxidation of the intermediates into $\mathrm{CO}_{2}$. The overall process can be summarized by the following proposed mechanism, where the zero-valent copper, transition metal ions $\mathrm{Co}(\mathrm{II})$ and $\mathrm{Cu}(\mathrm{II})$ embedded in the framework acting as the catalytic site underwent electron translation and activated PMS to generate $\mathrm{SO}_{4}{ }^{\cdot-}$ (eqn. (3)-(12)). ${ }^{35,41}$

In an aqueous solution:

$$
\begin{aligned}
& \mathrm{Co}^{2+}+\mathrm{HSO}_{5}{ }^{-} \rightarrow \mathrm{Co}^{3+}+\mathrm{SO}_{4}{ }^{--}+\mathrm{OH}^{-} \\
& \mathrm{Cu}^{2+}+\mathrm{HSO}_{5}{ }^{-} \rightarrow \mathrm{Cu}^{3+}+\mathrm{SO}_{4}{ }^{--}+\mathrm{OH}^{-}
\end{aligned}
$$

In pores and on the surface of $\mathrm{Cu} @ \mathrm{Co}-\mathrm{MOFs}-3$ :

$$
\equiv \mathrm{Co}(\mathrm{II})+\mathrm{HSO}_{5}{ }^{-} \rightarrow \equiv \mathrm{Co}(\mathrm{II})-(\mathrm{HO}) \mathrm{OSO}_{3}{ }^{-}
$$



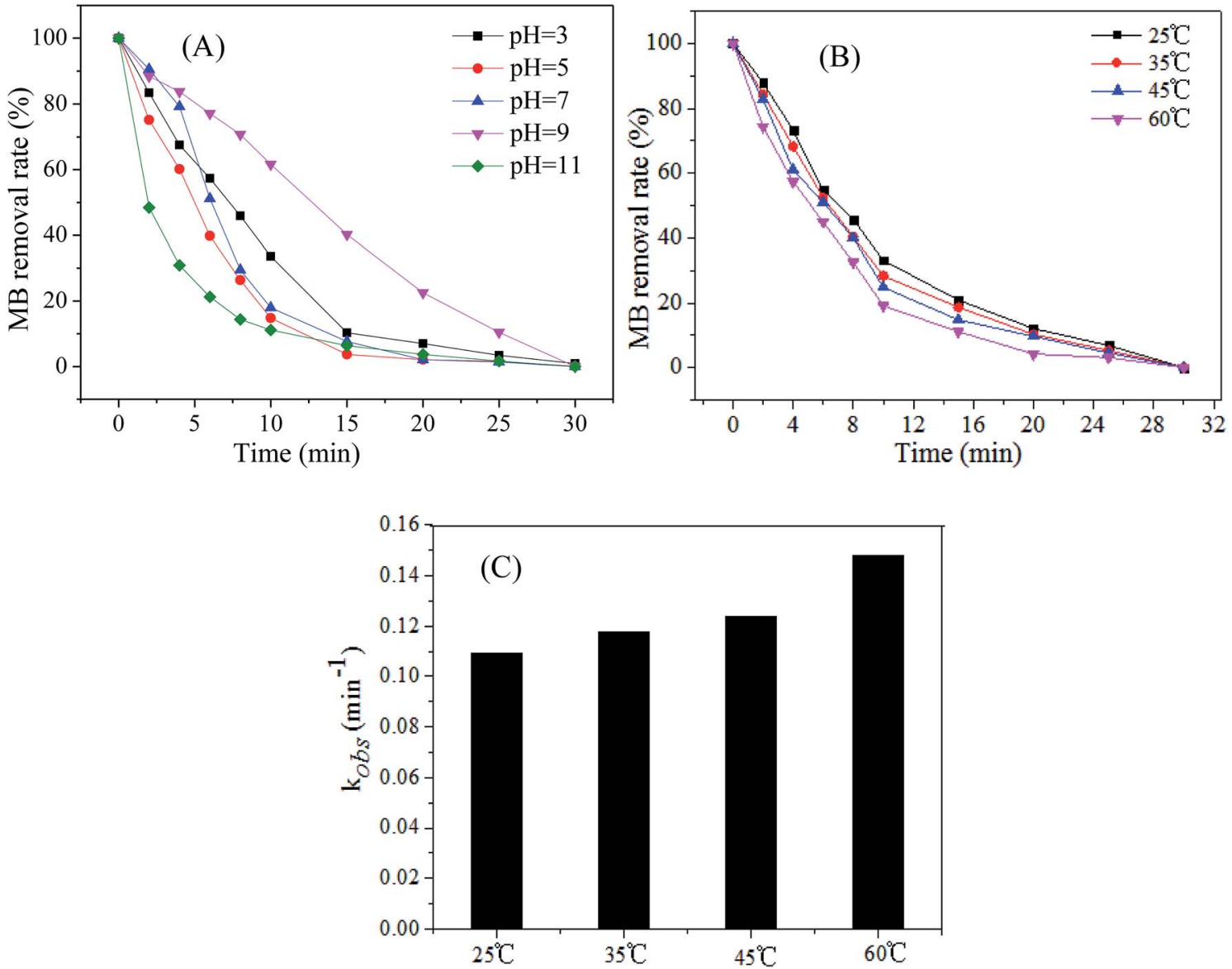

Fig. 7 (A) Effect of initial $\mathrm{pH}$ on the $\mathrm{MB}$ removal rate; $(\mathrm{B})$ effect of temperature on the MB removal rate; (C) effect of temperature on the removal rate constants of MB. Experiment condition: $\mathrm{PMS}=2 \mathrm{mM}, \mathrm{MB}=0.2 \mathrm{mM}, \mathrm{Cu}$ (C) Co-MOFs-3 $=0.2 \mathrm{~g} \mathrm{~L}-1, T=25^{\circ} \mathrm{C}$.

$$
\begin{gathered}
\equiv \mathrm{Co}(\mathrm{ii})-(\mathrm{HO}) \mathrm{OSO}_{3}{ }^{-} \rightarrow \equiv \mathrm{Co}(\mathrm{iii})-\mathrm{OH}^{-}+\mathrm{SO}_{4}{ }^{-} \\
\equiv \mathrm{Co}(\mathrm{iii})-\mathrm{OH}^{-}+\mathrm{HSO}_{5}{ }^{-} \rightarrow \equiv \mathrm{Co}(\mathrm{ii})-\mathrm{OOSO}_{3}{ }^{-}+\mathrm{H}_{2} \mathrm{O} \\
2 \equiv \mathrm{Co}(\mathrm{II})-\mathrm{OOSO}_{3}{ }^{-} \rightarrow 2 \equiv \mathrm{Co}(\mathrm{II})+\mathrm{O}_{2}+\mathrm{SO}_{4}{ }^{-}
\end{gathered}
$$

$$
\begin{gathered}
\equiv \mathrm{Cu}(\mathrm{II})+\mathrm{S}_{2} \mathrm{O}_{8}{ }^{2-} \rightarrow \equiv \mathrm{Cu}(\mathrm{III})+\mathrm{SO}_{4}{ }^{--}+\mathrm{SO}_{4}{ }^{2-} \\
\equiv \mathrm{Cu}+\mathrm{O}_{2}+\mathrm{H}_{2} \mathrm{O} \rightarrow 2 \mathrm{Cu}^{+}+\mathrm{H}_{2} \mathrm{O}_{2}+2 \mathrm{OH}^{-} \\
\equiv \mathrm{Cu}+\mathrm{O}_{2}+\mathrm{H}_{2} \mathrm{O} \rightarrow \mathrm{Cu}^{2+}+\mathrm{H}_{2} \mathrm{O}_{2}+2 \mathrm{OH}^{-}
\end{gathered}
$$
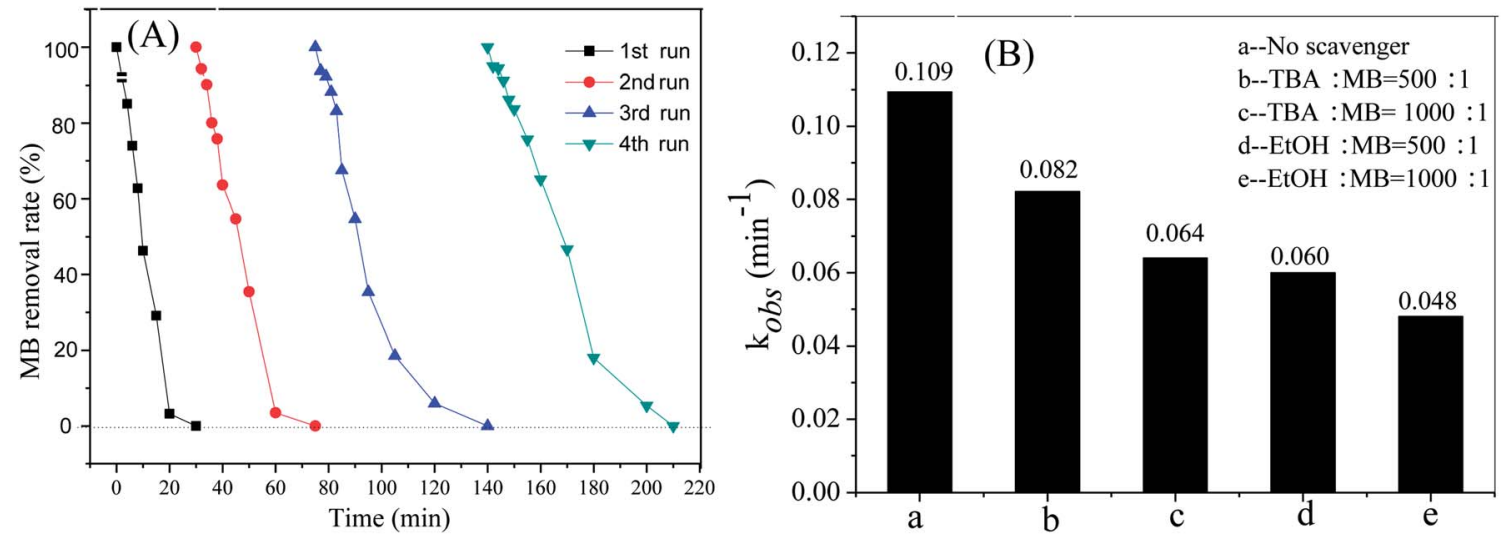

Fig. 8 (A) MB removal rate in multi-cycle batch experiments; (B) effect of scavenger on first-order kinetic constants of $M B$. Experiment condition: (A) PMS $=4 \mathrm{mM}, \mathrm{MB}=0.2 \mathrm{mM}$, CuCCo-MOFs-3 $=0.2 \mathrm{~g} \mathrm{~L}^{-1}, T=25^{\circ} \mathrm{C}$; (B) PMS $=2 \mathrm{mM}, \mathrm{MB}=0.2 \mathrm{mM}, \mathrm{OG}=0.2 \mathrm{mM}, \mathrm{CuCCo}-\mathrm{MOFs}-$ $3=0.1 \mathrm{~g} \mathrm{~L}^{-1}, T=25^{\circ} \mathrm{C}$. 


$$
\begin{gathered}
\mathrm{Cu}^{+}+\mathrm{H}_{2} \mathrm{O}_{2}+\mathrm{H}^{+} \rightarrow \mathrm{Cu}^{2+}+\mathrm{H}_{2} \mathrm{O}+\cdot \mathrm{OH} \\
\mathrm{Cu}^{2+}+\mathrm{H}_{2} \mathrm{O}_{2} \rightarrow \mathrm{Cu}^{+}+\mathrm{H}^{+}+\cdot \mathrm{O}_{2}{ }^{-}
\end{gathered}
$$

\section{Conclusion}

In this study, for the first time, we reported the synthesis of the $\mathrm{Cu}$ particle-doped Co-MOFs (Cu@Co-MOFs) by a hydrothermal method. The characterization results with XRD, FT-IR, SEM, EDS and XPS confirmed the incorporation of the zero-valent copper on the surface of the Co-MOFs structure. The catalytic performance of $\mathrm{Cu} @ \mathrm{Co}-\mathrm{MOF}$ obtained using different preparation conditions were studied for the oxidative removal of $\mathrm{MB}$ in the presence of PMS and PDS. It turned out that the Cu@CoMOFs demonstrated a superior catalytic performance towards PMS for the removal of $\mathrm{MB}$ at a wide $\mathrm{pH}$ range. The best removal result was achieved with $\mathrm{Cu} @ \mathrm{Co}-\mathrm{MOFs}-3$, where $100 \%$ of $\mathrm{MB}$ was removed within $30 \mathrm{~min}$. The $\mathrm{MB}$ removal rate increased with the increase in the initial $\mathrm{pH}$ values, reaction temperature and catalyst dosages. The percent of MB removal decreased with an increase in the PMS concentration, and the optimum PMS concentration was determined to be $2.0 \mathrm{mM}$. Moreover, the $\mathrm{Cu}$ @Co-MOFs-3 showed relative stability in the catalytic process with a low decline in the MB removal in four runs. The MB removal mechanism was proposed, which was ascribed to the oxidation of the primary reactive species $\left(\mathrm{SO}_{4}{ }^{-}\right.$and $\left.\cdot \mathrm{OH}\right)$. The findings of this study provide important insights into the development of heterogeneous PMS catalysts for wastewater treatment.

\section{Conflicts of interest}

There are no conflicts to declare.

\section{Acknowledgements}

This work was supported by National Natural Science Foundation of China (No. 51808177).

\section{References}

1 N. S. C. Y. Anjaneyulu and D. S. S. Raj, Decolourization of industrial effluents-available methods and emerging technologies-a review, Rev. Environ. Sci. Bio/Technol., 2005, 4, 245-273.

2 J. Liang, X. A. Ning, J. Sun, J. Song, J. Lu, H. Cai and Y. Hong, Toxicity evaluation of textile dyeing effluent and its possible relationship with chemical oxygen demand, Ecotoxicol. Environ. Saf., 2018, 166, 56-62.

3 M. Momina, M. Shahadat and S. Isamil, Regeneration performance of clay-based adsorbents for the removal of industrial dyes: a review, RSC Adv., 2018, 8, 24571-24587.

4 A. Kausar, M. Iqbal, A. Javed, K. Aftab, Z.-i.-H. Nazli, H. N. Bhatti and S. Nouren, Dyes adsorption using clay and modified clay: a review, J. Mol. Liq., 2018, 256, 395-407.
5 X. Cao, H. Wang, S. Zhang, O. Nishimura and X. Li, Azo dye degradation pathway and bacterial community structure in biofilm electrode reactors, Chemosphere, 2018, 208, 219-225.

6 Z. Zhao, J. Liu, C. Tai, Q. Zhou, J. Hu and G. Jiang, Rapid decolorization of water soluble azo-dyes by nanosized zerovalent iron immobilized on the exchange resin, Sci. China, Ser. B: Chem., 2008, 51, 186-192.

7 H. Zhao, Y. Chen, Q. Peng, Q. Wang and G. Zhao, Catalytic activity of $\mathrm{MOF}(2 \mathrm{Fe} / \mathrm{Co}) /$ carbon aerogel for improving $\mathrm{H}_{2} \mathrm{O}_{2}$ and $\mathrm{OH}$ generation in solar photo-electro-Fenton process, Appl. Catal., B, 2017, 203, 127-137.

8 Y. L. Oon, S. A. Ong, L. N. Ho, Y. S. Wong, F. A. Dahalan, Y. S. Oon, H. K. Lehl, W. E. Thung and N. Nordin, Up-flow constructed wetland-microbial fuel cell for azo dye, saline, nitrate remediation and bioelectricity generation: from waste to energy approach, Bioresour. Technol., 2018, 266, 97-108.

9 M. D. M. Bodzek and K. Luks-Betlej, Application of membrane techniques to water purification. Removal of phthalates, Desalination, 2004, 162, 121-128.

10 Y. Wu, R. Prulho, M. Brigante, W. Dong, K. Hanna and G. Mailhot, Activation of persulfate by $\mathrm{Fe}(\mathrm{III})$ species: implications for 4-tert-butylphenol degradation, J. Hazard. Mater., 2017, 322, 380-386.

11 H. Peng, L. Xu, W. Zhang, F. Liu, X. Lu, W. Lu, M. Danish and K. Lin, Different kinds of persulfate activation with base for the oxidation and mechanism of BDE209 in a spiked soil system, Sci. Total Environ., 2017, 574, 307-313.

12 D. Xia, Y. Li, G. Huang, R. Yin, T. An, G. Li, H. Zhao, A. Lu and P. K. Wong, Activation of persulfates by natural magnetic pyrrhotite for water disinfection: efficiency, mechanisms, and stability, Water Res., 2017, 112, 236-247.

13 S. Yan, R. Guo, Y. Du and H. Zhang, Hydronium jarosite activation of peroxymonosulfate for the oxidation of organic contaminant in an electrochemical reactor driven by microbial fuel cell, J. Hazard. Mater., 2017, 333, 358-368.

14 Y. Ding, H. Tang, S. Zhang, S. Wang and H. Tang, Efficient degradation of carbamazepine by easily recyclable microscaled $\mathrm{CuFeO}_{2}$ mediated heterogeneous activation of peroxymonosulfate, J. Hazard. Mater., 2016, 317, 686-694.

15 H. Li, J. Wan, Y. Ma and Y. Wang, Reaction pathway and oxidation mechanisms of dibutyl phthalate by persulfate activated with zero-valent iron, Sci. Total Environ., 2016, 562, 889-897.

16 W. Li, R. Orozco, N. Camargos and H. Liu, Mechanisms on the Impacts of Alkalinity, pH, and Chloride on PersulfateBased Groundwater Remediation, Environ. Sci. Technol., 2017, 51, 3948-3959.

17 Y. Zhou, J. Jiang, Y. Gao, J. Ma, S. Y. Pang, J. Li, X. T. Lu and L. P. Yuan, Activation of Peroxymonosulfate by Benzoquinone: A Novel Nonradical Oxidation Process, Environ. Sci. Technol., 2015, 49, 12941-12950.

$18 \mathrm{H}$. Li, J. Wan, Y. Ma, Y. Wang and M. Huang, Influence of particle size of zero-valent iron and dissolved silica on the reactivity of activated persulfate for degradation of acid orange 7, Chem. Eng. J., 2014, 237, 487-496. 
19 P. Shukla, H. Sun, S. Wang, H. M. Ang and M. O. Tadé, CoSBA-15 for heterogeneous oxidation of phenol with sulfate radical for wastewater treatment, Catal. Today, 2011, 175, 380-385.

20 M. R. Azhar, P. Vijay, M. O. Tade, H. Sun and S. Wang, Submicron sized water-stable metal organic framework (bio-MOF-11) for catalytic degradation of pharmaceuticals and personal care products, Chemosphere, 2018, 196, 105114.

21 V. K. Sharma and M. Feng, Water depollution using metalorganic frameworks-catalyzed advanced oxidation processes: a review, J. Hazard. Mater., 2017, DOI: 10.1016/ j.jhazmat.2017.09.043.

22 N. u. Qadir, S. A. M. Said and H. M. Bahaidarah, Structural stability of metal organic frameworks in aqueous media controlling factors and methods to improve hydrostability and hydrothermal cyclic stability, Microporous Mesoporous Mater., 2015, 201, 61-90.

23 L. Li, L. Guo, S. Pu, J. Wang, Q. Yang, Z. Zhang, Y. Yang, Q. Ren, S. Alnemrat and Z. Bao, A calcium-based microporous metal-organic framework for efficient adsorption separation of light hydrocarbons, Chem. Eng. J., 2019, 358, 446-455.

24 N. T. Xuan Huynh, V. Chihaia and D. N. Son, Hydrogen storage in MIL-88 series, J. Mater. Sci., 2018, 54, 3994-4010.

25 M. Pander, A. Żelichowska and W. Bury, Probing mesoporous Zr-MOF as drug delivery system for carboxylate functionalized molecules, Polyhedron, 2018, 156, 131-137.

26 K.-Y. A. Lin and H.-A. Chang, Zeolitic imidazole framework67 (ZIF-67) as a heterogeneous catalyst to activate peroxymonosulfate for degradation of rhodamine $B$ in water, J. Taiwan Inst. Chem. Eng., 2015, 53, 40-45.

27 Y. Gao, S. Li, Y. Li, L. Yao and H. Zhang, Accelerated photocatalytic degradation of organic pollutant over metalorganic framework MIL-53(Fe) under visible LED light mediated by persulfate, Appl. Catal., B, 2017, 202, 165-174.

28 X. Li, W. Guo, Z. Liu, R. Wang and H. Liu, Fe-based MOFs for efficient adsorption and degradation of acid orange 7 in aqueous solution via persulfate activation, Appl. Surf. Sci., 2016, 369, 130-136.

29 Z. Yang, X. Xu, X. Liang, C. Lei, Y. Wei, P. He, B. Lv, H. Ma and Z. Lei, MIL-53(Fe)-graphene nanocomposites: efficient visible-light photocatalysts for the selective oxidation of alcohols, Appl. Catal., B, 2016, 198, 112-123.

30 E.-H. Zhou, B.-H. Li, W.-X. Chen, Z. Luo, J. Liu, A. Singh, A. Kumar and J.-C. Jin, Photocatalytic degradation of organic dyes by a stable and biocompatible $\mathrm{Zn}$ (II) MOF having ferulic acid: experimental findings and theoretical correlation, J. Mol. Struct., 2017, 1149, 352-356.

31 H. Li, J. Wan, Y. Ma, Y. Wang, X. Chen and Z. Guan, Degradation of refractory dibutyl phthalate by peroxymonosulfate activated with novel catalysts cobalt metal-organic frameworks: mechanism, performance, and stability, J. Hazard. Mater., 2016, 318, 154-163.

32 H. Li, J. Qin, Y. Zhang, S. Xu, J. Du and J. Tang, The efficiency and mechanism of dibutyl phthalate removal by copperbased metal organic frameworks coupled with persulfate, RSC Adv., 2018, 8, 39352-39361.

33 X. Lou, C. Fang, Z. Geng, Y. Jin, D. Xiao, Z. Wang, J. Liu and Y. Guo, Significantly enhanced base activation of peroxymonosulfate by polyphosphates: kinetics and mechanism, Chemosphere, 2017, 173, 529-534.

34 Q. Ji, J. Li, Z. Xiong and B. Lai, Enhanced reactivity of microscale $\mathrm{Fe} / \mathrm{Cu}$ bimetallic particles $(\mathrm{mFe} / \mathrm{Cu})$ with persulfate (PS) for p-nitrophenol (PNP) removal in aqueous solution, Chemosphere, 2017, 172, 10-20.

35 G. Dong, Z. Ai and L. Zhang, Total aerobic destruction of azo contaminants with nanoscale zero-valent copper at neutral $\mathrm{pH}$ : promotion effect of in situ generated carbon center radicals, Water Res., 2014, 66, 22-30.

36 Y. Li, M. Xie, X. Zhang, Q. Liu, D. Lin, C. Xu, F. Xie and X. Sun, Co-MOF nanosheet array: a high-performance electrochemical sensor for non-enzymatic glucose detection, Sens. Actuators, B, 2019, 278, 126-132.

37 Y. Gu, D. Xie, Y. Wang, W. Qin, H. Zhang, G. Wang, Y. Zhang and $\mathrm{H}$. Zhao, Facile fabrication of composition-tunable Fe/ $\mathrm{Mg}$ bimetal-organic frameworks for exceptional arsenate removal, Chem. Eng. J., 2019, 357, 579-588.

38 C. D. Qi, X. T. Liu, J. Ma, C. Y. Lin, X. W. Li and H. J. Zhang, Activation of peroxymonosulfate by base: implications for the degradation of organic pollutants, Chemosphere, 2016, 151, 280-288.

39 J. Deng, Y. Shao, N. Gao, C. Tan, S. Zhou and X. Hu, CoFe ${ }_{2} \mathrm{O}_{4}$ magnetic nanoparticles as a highly active heterogeneous catalyst of oxone for the degradation of diclofenac in water, J. Hazard. Mater., 2013, 262, 836-844.

40 Y. Wang, H. Sun, X. Duan, H. M. Ang, M. O. Tadé and S. Wang, A new magnetic nano zero-valent iron encapsulated in carbon spheres for oxidative degradation of phenol, Appl. Catal., B, 2015, 172-173, 73-81.

41 T. Zhang, Y. Chen and T. Leiknes, Oxidation of Refractory Benzothiazoles with $\mathrm{PMS} / \mathrm{CuFe}_{2} \mathrm{O}_{4}$ : Kinetics and Transformation Intermediates, Environ. Sci. Technol., 2016, 50, 5864-5873. 